\title{
PREVALENCIA DE LA JURISDICCIÓN ESPECIAL PARA LA PAZ SOBRE LA COSA JUZGADA EN COLOMBIA
}

Berónica Narváez Mercado Ángel Andrés Torres Hernández Héctor Enrique Úrzola Berrío

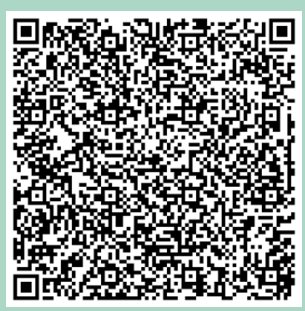




\section{PREVALENGIA DE LA JURISDIGGIÓN ESPEGIAL PARA LA PAZ SOBRE LA COSA JUZGADA EN GOLOMBIA}

Berónica Narváez Mercado ${ }^{1}$ Ángel Andrés Torres Hernández², Héctor Enrique Úrzola Berrio ${ }^{3}$

\section{Palabras claves}

Cosa juzgada, justicia transicional, sentencias, prevalencia.

\section{RESUMEN}

El objetivo de nuestro trabajo consistió en establecer si los fallos judiciales que sean proferidos por la Jurisdicción Especial para la Paz en la búsqueda de una paz duradera y sostenible, prevalecen sobre las decisiones sancionatorias que se hayan proferido en la jurisdicción ordinaria, la jurisdicción administrativa o los fallos disciplinarios, otorgando seguridad jurídica a los victimarios que se acojan a los Acuerdos de Paz y, por supuesto, a las víctimas que padecieron de las graves consecuencias del conflicto armado, para que se garantice el derecho a la verdad, la justicia, la reparación y la garantía de no repetición de los hechos delictivos, con la utilización de un sistema especial de justicia transicional. Teniendo en cuenta que es una investigación teórica y por tratarse de un tema controversial, se realizó un análisis documental de fuentes legales relativas al tema, de la doctrina nacional y extranjera así como de la jurisprudencia de las altas cortes nacionales y de la Corte Interamericana de Derechos Humanos; además, se revisó la normativa específica como el Acuerdo Final para la terminación del conflicto y la construcción de una paz estable y duradera, el Acto Legislativo No. 01 de 2017, la ley de amnistía, asimismo, la ley que establece el procedimiento de la JEP.

1. Doctorante en Derecho de la Universidad Libre de Colombia. MBA de la Escuela Libre de Derecho de Costa Rica, Abogada, Conciliadora y Docente Investigadora, Directora del Grupo de Investigaciones Socio jurídicas GISCER de la Facultad de Derecho y Ciencias Políticas de la Corporación Universitaria del Caribe. Email: beronica.narvaez@cecar.edu.co Orcid: https://orcid.org/0000-0003-4161-9275

2. Doctorando en Derecho. Magíster en Derecho. Especialista en Derecho Tributario. Especialista en Gerencia de la Hacienda Pública. Abogado y Contador Público. Docente Investigador de la Corporación Universitaria Antonio José de Sucre. Email: angel_torres@corposucre.edu.co Orcid: https://orcid.org/0000-0002-0657-7527

3. Magíster en Educación. Especialista en Investigación. Licenciado en Ciencias de la Educación. Docente y Director de Investigación en la Corporación Universitaria Antonio José de Sucre. Email: hector_urzola@corposucre.edu.co. Orcid: https://orcid.org/0000-0003-1201-0006 


\section{Keywords}

\section{Judged thing,}

transitional

justice, judgments, prevalence
Como resultado, se encontró que las providencias judiciales de la Jurisdicción Especial para la paz, tendrán prevalencia sobre las sanciones penales, disciplinarias y administrativas que se hayan proferido por parte de la justicia ordinaria o por quien corresponda; esto se pretende a través de la utilización de una justicia transicional que se dispone como restaurativa, con el fin de aplicar indulto, amnistía o penas alternativas para los actores del conflicto en la búsqueda de una paz duradera y sostenible.

\section{Abstract}

The objective of our work is to establish whether the judicial decisions that are made by the Special Jurisdiction for Peace in the search for a lasting and sustainable peace prevail over the sanctioning decisions that have been issued in the ordinary jurisdiction, administrative jurisdiction or disciplinary decisions, granting legal certainty to the offenders who accept the Peace Accords and of course to the victims who suffered from the serious consequences of the armed conflict, so that the right to truth, justice, reparation and the guarantee of non-repetition of criminal acts, with the use of a special transitional justice system. Taking into account that it is a theoretical investigation and because it is a controversial issue, a documentary analysis of legal sources related to the subject, of national and foreign doctrine and jurisprudence of the national high courts and the Inter-American Court of Human Rights was carried out, In addition, the specific regulations such as the Final Agreement for the termination of the conflict and the construction of a stable and lasting peace, Legislative Act No. 01 of 2017, the amnesty law and the law establishing the JEP procedure were reviewed. As a result, it was found that the judicial provisions of the Special Jurisdiction for peace will have a prevalence over the penal, disciplinary and administrative sanctions that have been issued by the ordinary courts or by whom they may correspond; This is intended through the use of transitional justice that is available as restorative, in order to apply pardon, amnesty or alternative penalties for the actors of the conflict in the search for a lasting and sustainable peace. 


\section{INTRODUGGIÓN}

"Si el hombre fracasa en conciliar la justicia y la libertad, fracasa en todo" Albert Camus

La investigación data de la Jurisdicción Especial para la Paz, contenida en el Acuerdo de Paz, como modelo de justicia transicional, desde su origen normativo para la implementación en la búsqueda de la paz, se desarrolla cada uno dos propósitos contenidos en esta justicia especial, como los pilares de verdad, justicia, reparación y garantía de no repetición, como herramienta que propone una justicia restaurativa que propenda a la reconciliación de los actores en conflicto.

Por otra parte, estudiaremos la cosa juzgada como institución jurídica que busca, por un lado, garantizar a la sociedad que la administración de justicia cumplió con la finalidad de juzgar a quienes cometieron conductas delictivas y, por otra parte, a estos últimos, que ese juzgamiento es acorde al ordenamiento jurídico y que no se le puede volver a investigar, enjuiciar ni sentenciar sobre lo ya fallado, asimismo, se revisa el enfoque que tiene la cosa juzgada en el marco de la justicia transicional.

Por último, se analizará la normatividad específica sobre la Jurisdicción Especial para la paz contenida en el Acuerdo Final para la terminación del conflicto y la construcción de una paz estable y duradera, en la búsqueda de los principios que la rigen. Se hace énfasis en los juzgamientos anteriores a esta nueva jurisdicción para determinar si la cosa juzgada por la JEP tendría prevalencia sobre dichos fallos. En este orden de ideas, corresponde resolver en esta investigación la siguiente pregunta: ¿Las decisiones judiciales y administrativas sancionatorias pueden ser estudiadas, tramitadas y falladas por la Jurisdicción Especial para la Paz?

\section{Metodología}

Este trabajo de investigación es de tipo teórico y se aborda bajo los parámetros que plantea la investigación cualitativa en ciencias sociales, esto permite el establecimiento de un método científico para abordar e interactuar con el objeto de investigación.

A fin de emprender esta investigación se selecciona como ruta metodológica la que ofrece la investigación documental e histórica, en el marco multicíclico de la investigación cualitativa. En ella, la hermenéutica (remitida al método hermenéutico-documentalhistórico) fue el enfoque metodológico con el cual se acercó a la interpretación de los textos y contextos señalados, con el aporte teórico del análisis de contenido.

\section{JURISDIGGIÓN ESPEGIAL PARA LA PAZ, UN MODELO DE JUSTICIA TRANSICIONAL}

Se precisa hacer énfasis en el modelo jurídico en el cual se enmarca esta jurisdicción, este es, precisamente, la justicia transicional, sistema que es definido como:

Una modalidad jurídica que busca colaborar en la conversión de un Estado de violencia y de ausencia de garantías democráticas, a un Estado de paz y respeto por las libertades civiles; excepcional, contingente y especifica; 
un mecanismo tendiente al logro de la justicia, la verdad, la reparación y la garantía de no repetición, y un elemento insoslayable para la consolidación de la paz de la paz. (Bernal \& Alvarez, 2009, p. 60)

En tanto que, en el libro Derecho y lógicas de la justicia. Un análisis socio-jurídico desde la academia, los autores analizan el Informe del Secretario General de Naciones Unidas de 2004 (The Rule of Law and Transitional Justice in Conflict and Post-Conflict Societies) y luego el UN-IDDRS, 2006, que define justicia transicional como:

Medidas utilizadas por una sociedad para lidiar con un legado de abusos contra los Derechos Humanos a gran escala a fin de facilitar la rendición de cuentas, servir a la justicia y lograr la reconciliación. Las medidas de justicia transicional incluyen respuestas judiciales y no judiciales, como enjuiciamientos, comisiones de la verdad, programas de reparación para las víctimas y herramientas para la reforma institucional, como la investigación. Cualquiera que sea la combinación elegida debe estar de acuerdo con los estándares y estándares legales internacionales. (Nárvaez, et al., p. 55)

Los procesos de transición, se pueden clasificar según la forma como han resuelto las tensiones entre la justicia y la paz en cuatro tipos básicos: indultos amnésicos, perdones compensatorios, perdones responsables y transiciones punitivas. Así, los perdones amnésicos no contemplan la verdad ni reparar a las víctimas, mientras que los perdones compensatorios van acompañados de la implementación de comisiones de la verdad, además de algunas medidas correctivas para las víctimas.

Es, entonces, la justicia transicional el referente jurídico macro en que se basa la Jurisdicción de Paz con la que el Estado colombiano pretende alcanzar la convivencia social como contextualización de paz, amoldado en sus pilares fundamentales que son:

- El derecho a la verdad;

- la reparación, tanto de las víctimas directas como de la sociedad en general como victimas indirectas;

- la justicia, enfocada como deber estatal $\mathrm{y}$;

- la garantía de que los hechos generadores de conflicto no se vuelvan a repetir.

En primer lugar, el derecho a la verdad implica que las víctimas de graves violaciones de los Derechos Humanos y del derecho internacional humanitario, así como sus familiares, tienen el derecho a un recurso efectivo. Esto implica el derecho a saber la verdad acerca del abuso que han sufrido, incluyendo la posibilidad de identificar a los perpetradores, las causas que originaron tales violaciones y, de ser el caso, la suerte final o el paradero de las personas desaparecidas de manera forzada González \& Varney, 2013).

No obstante lo anterior, deberemos entender el derecho a la verdad, no solo dirigido a la víctima directa del conflicto, sino que, además, está característica o pilar de la justicia transicional deberá enfocarse en la sociedad que también, de manera indirecta, padece del conflicto y se le debe garantizar este derecho. 
El derecho a la verdad tiene una dimensión colectiva cuyo fin es "preservar del olvido a la memoria colectiva" (Corte Constitucional, 2015) y una dimensión individual, cuya efectividad se realiza, fundamentalmente, en el ámbito judicial, a través del derecho de las víctimas a un recurso judicial efectivo, tal como lo ha reconocido la jurisprudencia de esta Corte. En este sentido, el derecho a conocer la verdad:

Presenta una faceta subjetiva en cuanto a que, independientemente de las acciones que puedan entablar ante la justicia, las víctimas, así como sus familias y allegados, tienen derecho a conocer la verdad acerca de las circunstancias en que se cometieron las violaciones y, en caso de fallecimiento o desaparición, acerca de la suerte que corrió la víctima. (Corte Constitucional, 2015, sección DERECHO A LA VERDAD-Concepto/DERECHO A LA VERDAD-Alcance)

En segundo lugar, se presenta en este orden jurídico especial el derecho a la justicia, el cual tiene dos enfoques, el primero se refiere a que el Estado no puede renunciar a su obligación de Juzgar a quienes cometan delitos, más aún si se tratan de delitos en contra de la humanidad, con basamento en principio de la lucha contra la impunidad, en tal virtud, bajo este modelo, la garantía de justicia impone al Estado la obligación de investigar, juzgar y condenar a penas adecuadas a los responsables de las conductas delictivas y evitar la impunidad. Eso tiene su fundamento en lo siguiente:

Artículo 2 del Pacto internacional de Derechos Civiles y Políticos, los artículos 4, 5 y 6 de la Convención contra la Tortura y otros tratos o Penas Crueles, Inhumanos y Degradantes, los artículos 1, 3, 7-10 de la Convención Interamericana para prevenir y sancionar la tortura, los artículos 1, 3, 7-10 de la Convención Interamericana sobre Desaparición Forzada de Personas, los artículos 18 y 24 de la Declaración Americana de Derechos Humanos (...), los artículos 1.1, 2, 8 y 25 de la Convención Americana sobre Derechos Humanos, el artículo 8 de la Declaración Universal de Derechos Humanos (...) y 8 de la Convención Americana de Derechos Humanos (...) relativos al derecho de acceso a los tribunales para hacer valer los derechos mediante los recursos ágiles y efectivos. (Corte Constitucional, 2016, art. 2)

Además, se constituye en un referente para la víctima en la búsqueda de justicia, que ve en la administración de justicia una herramienta que evite el uso de las vías de hecho por parte de quienes padecieron, por ello, este pilar fundamental también es visto como la posibilidad de las víctimas de hacer valer sus derechos, beneficiándose de un recurso equitativo y efectivo, sobre todo para logar que su opresor sea juzgado y obtener reparación (Hernández, 2018).

En tercer lugar, tenemos la reparación, que pretenden reconocer y responder ante los daños sufridos por las víctimas de violaciones sistemáticas de los Derechos Humanos (Carranza, s.f.). Debe realizarse de manera integral y se entiende como la obligación del Estado, cuya finalidad es devolver a la víctima al estado en el que se encontraba 
con anterioridad al hecho que originó tal condición.

Por lo tanto, el hecho victimizante con el cual se vulneraron los Derechos Humanos genera en favor de la persona que lo padeció el derecho fundamental a la reparación integral, lo que se hace efectivo del siguiente modo:

A través de la restitución, la indemnización, la rehabilitación, la satisfacción y la garantía de no repetición consagradas en el Derecho Internacional, que se desprenden de la condición de víctimas y que deben ser salvaguardados por el Estado independientemente de la identificación, aprehensión, enjuiciamiento o condena de los victimarios. (Corte Constitucional, 2017)

Por último, tenemos la garantía de no repetición, esta debe ser vista hacia el futuro, en especial, con miras a las generaciones siguientes, con el propósito evitar que padezcan las mismas situaciones sociales de conflicto armado. De conformidad con la Corte Constitucional la garantía de no repetición está compuesta por "todas las acciones dirigidas a impedir que vuelvan a realizarse conductas con las cuales se afectaron los derechos de las víctimas, las cuales deben ser adecuadas a la naturaleza y magnitud de la ofensa". Se encuentra directamente relacionada con la obligación del Estado de prevenir las graves violaciones de los Derechos Humanos que comprende la adopción de medidas de carácter jurídico, político, administrativo y cultural (Corte Constitución, 2014).
Estos cuatro pilares se erigen como la columna que soporta la justicia transicional, elementos que forman parte del sistema de justicia especial que se pretende aplicar en el Estado colombiano luego de suscribir el acuerdo de paz con el grupo guerrillero al margen de la ley (FARG-EP), a través de un tribunal regulado por unas normas exclusiva y que se conoce como Jurisdicción Especial para la Paz.

La Jurisdicción Especial para la Paz (JEP) es el componente de justicia del Sistema Integral de Verdad, Justicia, Reparación y no Repetición, creado por el Acuerdo de Paz entre el Gobierno Nacional y las FARCEP, tiene la función de administrar justicia transicional y conocer de los delitos cometidos en el marco del conflicto armado que se hubieran cometido antes del 1 de diciembre de 2016, jurisdicción que tiene un término de existencia no superior a 20 años.

La JEP fue creada para satisfacer los derechos de las víctimas a la justicia, ofrecerles verdad y contribuir a su reparación con el propósito de construir una paz estable y duradera (Jurisdicción Especial para la Paz, 2016). En este orden de ideas, tenemos, entonces, un tribunal en Colombia creado bajo el modelo de justicia transicional, el cual tendrá la responsabilidad de administrar justicia por término definido sobre los delitos que se cometieron con ocasión al conflicto armado y que fueron ocurridos con anterioridad a la firma de los mismos. Jurisdicción que, sobre todo, deberá propender por el esclarecimiento de la verdad, garantizar la reparación integral de las víctimas, impartir justicia y constituirse en aval para que en la 
sociedad no se vuelvan a repetir los hechos que generadores de conflicto.

\section{LA GOSA JUZGADA EN LA JURISDIGGIÓN ESPEGIAL PARA LA PAZ}

Antes de abordar el tema del juzgamiento por parte de la Jurisdicción Especial para la Paz, es pertinente revisar lo que respecta a la cosa juzgada, conocido también como principio de non bis in ídem, que de acuerdo con el art. 29 de la Constitución: "Toda persona tiene derecho a no ser juzgada dos veces por el mismo hecho. Esta prohibición de doble juicio recibe el nombre de non bis in ídem, y ha sido reconocido por este tribunal constitucional como un derecho fundamental autónomo". Este implica que es contrario a la Constitución iniciar un nuevo proceso sancionatorio en contra de una persona que ya fue juzgada por esos mismos hechos, por lo que se prohíbe una nueva investigación, juicio o condena en contra de la persona que ya fue sometida al poder punitivo del Estado.

El principio de non bis in idem se encuentra ubicado en el centro de las garantías procesales comprendidas por el derecho al debido proceso. Este principio jurídico, que constituye, sin lugar a dudas, el efecto de mayor relevancia del proceso, viene a solventar la quiebra de la seguridad jurídica supuesta por la eventual situación de absoluta desprotección jurídica en la que se encontraría la sociedad, si las resoluciones judiciales se mantuviesen pendientes, de manera indefinida, en el tiempo, de una revisión o, en su caso, de un nuevo conocimiento judicial (Calaza, 2009).

La finalidad primordial de este principio radica en impedir que la decisión en firme sea objeto de nueva revisión o debate, o de instancias adicionales a las ya cumplidas, o que se reabra el caso judicial dilucidado mediante el fallo que reviste ese carácter, "con total independencia de su sentido o alcances, dotando de estabilidad y certeza las relaciones jurídicas y dejando espacio libre para que nuevos asuntos pasen a ser ventilados en los estrados judiciales" (Corte Constitucional, 1992).

En el caso del derecho penal se condena la actuación, es decir, la adecuación de una conducta que se enmarca en la prohibición normativa y que trae consigo una pena, dicho acto es conocido como delito, el cual, una vez queda juzgado, no podrá recaer sobre esta conducta una nueva sentencia ni levantarse nuevo proceso. Ahora bien, la pretensión del acuerdo de paz con la implementación de los puntos pactados, entre ellos el de la Jurisdicción Especial para la Paz, tiene como principios el componente de justicia del Sistema Integral de Verdad, Justicia, Reparación y No Repetición, en adelante el SIVJRNR, se denomina Jurisdicción Especial para la Paz.

Los objetivos del componente de justicia del SIVJRNR son:

Satisfacer el derecho de las víctimas a la justicia, ofrecer verdad a la sociedad colombiana, proteger los derechos de las víctimas, contribuir al logro de una paz estable y duradera, y adoptar decisiones que otorguen plena seguridad jurídica a quienes participaron de manera directa o indirecta en el conflicto armado interno, respecto a hechos cometidos en el marco del mismo y durante este que supongan graves infracciones del 
Derecho Internacional Humanitario y graves violaciones de los Derechos Humanos. (Gobierno Nacional de Colombia, 2016, p. 143)

En ese orden de ideas, corresponderá a la JEP, la responsabilidad de implementar justicia profiriendo fallos que garanticen, no solo los derechos a la verdad y a la justicia de las victimas junto con la contribución del logro de una paz duradera y sostenible, sino que además, ese juzgamiento debe estar brindado de seguridad jurídica sobre al victimario, es decir, aquella persona que participó de manera directa o indirecta en el conflicto armado interno. Indica entonces que aquellas personas que se acojan a esta jurisdicción se les deberán garantizar que lo ya juzgado está dotado de un valor definitivo e inmutable, en el entendido de que, a los funcionarios judiciales, a las partes o víctimas no podrán volver a entablar el mismo litigio.

Ese fallo, providencia o cosa juzgada deberá garantizar dos matices relevantes, el primero de ellos está dado en el orden interno, por cuanto se prohíbe cualquier estudio, investigación o juzgamiento por parte de los organismos del Estado al sujeto activo de la conducta que ya fue sancionada o absuelta en juicio por la jurisdicción especial que tienen la competencia, como principio de no ser juzgado nunca dos veces por lo mismo en el ordenamiento jurídico interno.

Por otra parte, deberá tener en cuenta la jurisdicción que existen organismos internacionales protectores de los Derechos Humanos con los cuales el Estado colombiano ha suscrito convenios para el juzgamiento de estos delitos como lo es la Corte Penal Internacional, quiere decir, entonces, que si la cosa juzgada en delitos de lesa humanidad no está acorde a los parámetros del derecho internacional consuetudinario, este tribunal internacional podría tener competencia sobre lo ya juzgado, aspecto que la JEP deberá evitar en sus sentencias.

Por lo tanto, podemos precisar que la cosa juzgada por la Jurisdicción especial para la paz deberá cumplir con la función negativa y positiva de este principio, es decir, la cosa juzgada tiene "como función negativa prohibir a los funcionarios judiciales conocer, tramitar y fallar sobre lo resuelto, y como función positiva, dotar de seguridad a las relaciones jurídicas y al ordenamiento jurídico" (Corte Constitucional, 2001), alcances o compromisos que en estricto derecho deberán estar representados plenamente en las providencias de su competencia.

Lo anterior, de manera indistinta si corresponden a personas que jamás han sido juzgadas y a quienes ya fueron condenados, en el entendido de que al acogerse a los acuerdos de paz, de manera integral, buscan el cumplimiento de los componentes de la justicia transicional y del Sistema Integral de Verdad, Justicia, Reparación y No Repetición que proponen lo pactado entre el gobierno y las FARC-EP.

El mismo acuerdo de paz señala, con respecto a la cosa juzgada, que una vez se finalice el conflicto, se podrá indultar o amnistiar a quienes hayan sido sancionado, tal y como lo señala el punto 23. 5.1.2 Justicia, al disponer:

23.- A la finalización de las hostilidades, de acuerdo con el DIH, el Estado colombiano puede otorgar la amnistía "más amplia posible". A los rebeldes 
que pertenezcan a organizaciones que hayan suscrito un acuerdo final de paz, según lo establecido en el numeral 10, así como a aquellas personas que hayan sido acusadas o condenadas por delitos políticos o conexos mediante providencias proferidas por la justicia, se otorgará la más amplia amnistía posible, respetando lo establecido al respecto en el presente documento, conforme a lo indicado en el numeral 38. (Acuerdo final para la terminación del conflicto y la construcción de una paz estable y duradera, 2016, punto 23. 5.1.2 Justicia)

Se debe tener en cuenta, entonces, por parte de la Jurisdicción Especial para la Paz que en el universo de personas que debe juzgar se encuentran unas que no han tenido procesos o han salido ilesos de estos y otros sujetos activos de delitos que aunque ya fueron sancionados y soportan una condena penal en firme, con todas las garantías procesales, a estos últimos los puede procesar nuevamente la JEP, mejorando su condición actual, ya sea mediante el indulto o la amnistía. Es apenas obvio que tratándose de graves violaciones a los Derechos Humanos o crímenes de guerra, no es posible aplicar este tratamiento, no obstante, para estos casos, sí existen prebendas en los acuerdos, pero no al punto de ser indultados o amnistiados, precisamente por la naturaleza de dichas conductas.

\section{¿Predomina la JEP sobre la cosa juzgada?}

Para responder este interrogante se realiza un esbozo utilizando el método deductivo, partiendo de lo general hacia lo particular en cuanto a normatividad se refiere, así las cosas, inicialmente revisamos la constitución con las normas que en ella se incorporan como son el acuerdo de paz, el Acto Legislativo 01 de 2017 para llegar a la recién expedida Ley 1922 de 2019 por medio de las cuales se adoptan unas reglas de procedimiento para la jurisdicción especial para la paz y cualquier otra disposición al respecto.

En primer lugar, debemos entender que es posible establecer que los Estados, entre ellos el colombiano, gozan de la autonomía para establecer jurisdicciones o sistemas jurídicos especiales de acuerdo con la Carta de Naciones Unidas sobre la soberanía y libre autodeterminación de las naciones (Naciones Unidas, 1945) y por supuesto de acuerdo con lo establecido en los principios del derecho internacional, entre ellos el Derecho Internacional Humanitario y el Derecho Internacional de los Derechos Humanos y el Derecho Penal Internacional, razón por la cual se establece en el orden jurídico interno un organismo para el juzgamiento de quienes se acogen a los acuerdo de paz en la búsqueda de la convivencia social.

Por otra parte, y teniendo en cuenta el acuerdo de paz, contemplaron la amnistía, la cual estará condicionada únicamente a la terminación de la rebelión de las respectivas organizaciones armadas y al cabal cumplimiento de lo establecido en el acuerdo de paz; téngase en cuenta que además de la amnistía, también procesará el indulto para quienes se les estén adelantando procesos penales por rebelión y los demás delitos conexos y que se encuentren cobijados con los beneficios.

A su vez, el Acto Legislativo No. 01 de 2017, que incorpora a la constitución, de manera transitoria, las normas para la terminación 
del conflicto armado y la construcción de una paz estable y duradera. Esta contiene en su artículo 6 , transitorio, la prevalencia de la jurisdicción de la JEP sobre las demás jurisdicciones, obviamente, tratándose de los delitos que dicha jurisdicción se limita a juzgar. Así, el artículo dispone:

Artículo transitorio $6^{\circ}$. Competencia prevalente. El componente de justicia del SIVJRNR, conforme a lo establecido en el Acuerdo Final, prevalecerá sobre las actuaciones penales, disciplinarias o administrativas por conductas cometidas con ocasión, por causa o en relación directa o indirecta con el conflicto armado, al absorber la competencia exclusiva sobre dichas conductas.

Respecto a las sanciones o investigaciones disciplinarias o administrativas, incluidas las pecuniarias impuestas a personas naturales en cualquier jurisdicción, la competencia de la Jurisdicción Especial para la Paz se limitará bien a anular o extinguir la responsabilidad o la sanción disciplinaria o administrativa impuesta por conductas cometidas con ocasión, por causa o en relación directa o indirecta con el conflicto armado, o bien a revisar dichas sanciones, todo ello a solicitud del sancionado o investigado. En todo caso la solicitud no podrá llevar aparejada la reapertura de una investigación penal por los mismos hechos. En caso de que se solicite la revisión de la sanción impuesta o la extinción de la sanción y responsabilidad, será competente la Sección de Revisión del Tribunal para la Paz Respecto a los investigados, será competente la Sala de definición de situaciones jurídicas. (Congreso de la República, 2017, art. 6)

Además de esta norma supra, porque se trata de la constitución misma, el Estado Colombiano, con el propósito de adecuar su ordenamiento jurídico al propósito específico de la paz, profirió la Ley 1922 de 2018 "Por medio del cual se adoptan unas reglas de procedimiento para la jurisdicción especial para la paz", que se aplica a todos aquellos que se acojan a ella, por lo tanto, se les aplica el principio de prevalencia en donde la Jurisdicción Especial Para la Paz tendrá la competencia por encima de cualquier otra jurisdicción, sea de carácter ordinario o administrativo.

Este código procedimental que rige a la JEP contiene en su artículo 5 el desligamiento de otras jurisdicciones para quienes se acojan a la JEP y, por supuesto, a los beneficios contenidos en ellas talles como la amnistía, indulto, reducción de penas entre otros aspectos que se relacionan con el acogimiento de los Acuerdos de Paz, el artículo señalado anteriormente dispone:

Artículo 5. Persona compareciente a la JEP. La persona que se acogió o fue puesta a disposición de la JEP adquiere la calidad de compareciente, cuando ésta asume competencia, de conformidad con la Ley Estatutaria de la Administración de Justicia en la JEP. A partir de la presentación del escrito de acusación se considerará acusado. (Congreso de la República, 2018, art. 5)

Existe además en el ordenamiento jurídico colombiano otra normatividad referente al juzgamiento de los actores del conflicto a través de los principios establecidos en 
el acuerdo de paz, para la Jurisdicción Especial para la Paz; esta norma fue emitida inmediatamente después de la firma de los acuerdos y contiene los aspectos relativos al tratamiento judicial de la amnistía y el indulto, se trata de la Ley 1820 de 2016 "Por medio de la cual se dictan disposiciones sobre amnistía, indulto y tratamientos penales especiales y otras disposiciones". Dicha norma establece, en su artículo 4, cuando trata el alcance de la misma, que en ella se aplicarán todos y cada uno de los principios contenidos en el Acuerdo de Paz que crea la Jurisdicción Especial para la Paz, respecto al tratamiento de la amnistía, indulto y otros mecanismos penales diferenciados de extensión de responsabilidades y sanciones penales principales y accesorias, aplicándose también a las sanciones o investigaciones de tipo administrativo.

Cobra mucha importancia esta ley porque en su artículo 7 hace una precisión sobre la prevalencia de la Jurisdicción Especial para la Paz, sobre cualquier otra jurisdicción o procedimiento, el cual señala textualmente:

Artículo $7^{\circ}$. Prevalencia. Las amnistías, indultos y los tratamientos penales tales como la extinción de responsabilidades y sanciones penales y administrativas o renuncia del Estado a la persecución penal establecidos en el acuerdo de Jurisdicción Especial para la Paz, incluidos los diferenciados para agentes del Estado, prevalecerán sobre las actuaciones de cualquier jurisdicción o procedimiento, en especial sobre actuaciones penales, disciplinarias, administrativas, fiscales o de cualquier otro tipo, por conductas ocurridas en el marco del conflicto interno, por causa, con ocasión o en relación directa o indirecta a este.

La amnistía será un mecanismo de extinción de la acción penal, disciplinaria, administrativa y fiscal, cuya finalidad es otorgar seguridad jurídica a los integrantes de las FARCEP o a personas acusadas de serlo, tras la firma del Acuerdo Final de Paz con el Gobierno nacional y la finalización de las hostilidades, todo ello sin perjuicio de lo establecido en el artículo 41 sobre extinción de dominio. (Congreso de la República, 2016, art. 7)

Precisa, además, el articulado con respecto las sanciones disciplinarias y administrativas, la amnistía tendrá también el efecto de anular o extinguir cualquier tipo de responsabilidad o inclusive las sanciones de carácter disciplinario y administrativo cuando las conductas realizadas por el sancionado obedezcan a las relacionadas de manera directa o indirecta con el conflicto armado.

Debemos tener en cuenta que esta normatividad se encuentra enmarcada en principios básicos como el derecho de vivir en paz, el cual se encuentra consagrado en la Constitución colombiana; la integralidad para no tener tratamientos diferenciales entre actores del conflicto, incluyendo por supuesto a los agentes del Estado; el reconocimiento del delito político y conexos como la rebelión, con el ánimo de que se dicha amnistía sea lo más amplia posible y se realice acorde al Derecho Internacional Humanitario.

En este orden de ideas, con el propósito de alcanzar una paz estable y duradera que se refleje en la convivencia social de todos 
los colombianos, los acuerdos de paz y toda la reglamentación, incluida, por supuesto, la atinente a la Jurisdicción Espacial para la Paz, se aparta del derecho penal como última ratio y le apuesta a un modelo de justicia transicional que contiene una justicia restaurativa de acuerdo con las necesidades de los actores en conflicto (grupos al margen de la ley, victimas, agentes del Estado, terceros) con la búsqueda de la verdad, justicia, reparación y la garantía de no repetición.

Por lo anterior, este modelo permite que a quienes sean cobijado por los acuerdos de paz, se les aplique una justicia que prevalece sobre la justicia ordinaria, que haya podido o pueda sancionar a los implicados en el tipo de conductas señaladas en el acuerdo, sea a través de la amnistía, el indulto o la aplicación de penas alternativas, por ende, las decisiones tomadas en la Jurisdicción Especial para la Paz prevalecen sobre las que ya se hayan tomado y las que se estén investigando por la justicia ordinaria, administrativa o disciplinaria.

En síntesis, aquellas personas que fueron condenadas o sancionadas por pertenecer a grupos al margen de la ley dedicados a los delitos enmarcados en el acuerdo y conexos a los mismos, podrán acogerse a la Jurisdicción Especial para la Paz, tales como los miembros de grupos paramilitares, guerrilleros, terceros, políticos condenado. Para estas personas que se acojan a la jurisdicción especial, tendrán prevalencia los fallos que allí se emitan sobre cualquiera que se haya proferido en otra jurisdicción.

\section{Conclusiones}

Conforme a lo anteriormente expuesto, en cada capítulo de esta escrito, se concluye que la justicia transicional es un sistema jurídico especial aplicable a los países que presentan conflictos armados internos y que pretenden pasar de un Estado de guerra, a la búsqueda de una paz estable duradera y sostenible, como el Estado colombiano.

Además, el Acuerdo de Paz firmado entre el Estado colombiano y las FARC-EP contiene un Sistema Integral de Verdad, Justicia, Reparación y No Repetición que pretende reconocer a las víctimas como ciudadanos con derechos, para la búsqueda de la paz. También cabe resaltar que la reparación a las victimas debe ser integral, ello comprende no solo lo económico sino también lo intangible, como la verdad a través de la justicia restaurativa.

Así mismo, la finalidad de la cosa juzgada es otorgar un valor definitivo e inmutable a los fallos judiciales, con el ánimo de que la administración de justicia no vuelva a entablar el mismo litigio. Y, por último, que lo fallos judiciales de la Justicia Especial para la Paz prevalecen sobre las sentencias judiciales y administrativas que se hubieren proferido sobre los victimarios. 


\section{REFERENGIAS}

Acuerdo final para la terminación del conflicto y la construcción de una paz estable y duradera. (2016).

Bernal, G., \& Alvarez, N. (2009). Aprendizaje Significativo de la Ley de Justicia y Paz. Embajada de la República Federal de Alemania Bogotá.

Calaza, S. (2009). La Cosa Juzgada. Madrid.

Carranza, R. (s.f.). Reparaciones. Obtenido de ICTJ. Justicia, verdad y dignidad : https:// www.ictj.org/es/our-work/transitionaljustice-issues/reparaciones

Congreso de la República. (2016). Ley 1820. Por medio de la cual se dictan disposiciones sobre amnistía, indulto y tratamientos penales especiales y otras disposiciones. Imprenta Nacional.

Congreso de la República. (2017). Acto Legislativo. Por medio del cual se crea un título de disposiciones transitorias de la constitución para la terminación del conflicto armado y la construcción de una paz estable y duradera y se dictan otras disposiciones. Colombia: Imprenta Nacional.

Congreso de la República. (2018). Ley 1922. Por medio del cual se adoptan unas reglas de procedimiento para la jurisdicción especial para la paz. Impronta Nacional.

Corte Constitucional. (01 de octubre de 1992). Sentencia C-543. Expediente D-056 y D-092. Sala Plena. M.P. José Gregorio Hernández Galindo. Colombia. Obtenido de https://www.corteconstitucional.gov.co/ relatoria/2007/C-543-07.htm

Corte Constitucional. (25 de julio de 2001). Sentencia C-774. Expediente D- 3271. Sala Plena. M.P. Rodrigo Escobar Gil. Bogotá, Colombia. Obtenido de http://legal.legis.com. $\mathrm{co} /$ document?obra=jurcol\&document=jurcol_75992041be81f034e0430a010151f034
Corte Constitución. (30 de octubre de 2014). Sentencia C-795. Expediente D-10190. Sala Plena. M.P. Jorge Ivan Palacio Palacio. Obtenido de https:// www.corteconstitucional.gov.co/ relatoria/2000/C-795-00.htm

Corte Constitucional. (3 de julio de 2015). Sentencia T-418 M.P. Jorge Ignacio Pretelt Chaljub. Expediente: T-4.385.805. Colombia. Obtenido de https:// www.corteconstitucional.gov.co/ relatoria/2015/T-418-15.htm

Corte Constitucional. (31 de agosto de 2016). Sentencia C-47 1. Expediente: D-11236 y D-11241. M.P. Alejandro Linares Cantillo. Colombia. Obtenido de https://www.corteconstitucional.gov.co/ relatoria/2016/C-471-16.htm

Corte Constitucional. (13 de febrero de 2017). Sentencia T-083. Expediente T-5.711.182. M.P. Alejandro Linares Cantillo. Colombia. Obtenido de https://www.corteconstitucional.gov.co/ relatoria/2017/T-083-17.htm

\section{ESGRITO DE AMICUS GURIAE DE LA} FISCAL DE LA CORTE PENAL, RPZ0000001 y RPZ-003 (Ante la Corte

Constitucional de la República de Colombia 18 de octubre de 2017).

Gobierno Nacional de Colombia. (2016). Acuerdo final para la terminación del conflicto y la construcción de una paz estale y duradera. Bogotá. Obtenido de https:// www.cancilleria.gov.co/sites/default/files/ Fotos2016/12.11_1.2016nuevoacuerdofinal. pdf

González, E., \& Varney, H. (2013). En busca de la verdad. Elementos para la creación de una comisión de la verdad eficaz. Comisión de Amnistía del Ministerio de Justicia de Brasil, 13.

Hernández, E. (2018). Los Significados de la Reconciliación desde las voces de las Víctimas. Convergencia. Toluca. Obtenido 
de https://www.researchgate.net/

publication/26418562_Los_significados_de_

la_reconciliacion_desde_las_voces_de_las_

victimas

Jurisdicción Especial para la Paz. (1 de diciembre

de 2016). Obtenido de JEP: https://www.jep.

gov.co/Paginas/JEP/Jurisdiccion-Especial-

para-la-Paz.aspx

Naciones Unidas. (1945). Carta de las Naciones

Unidas.

Nárvaez, B., Ibarra, A., \& Aguas, J. (2018).

Comisiones de la Verdad y Derechos

Humanos. En B. Narváez, O. Ramírez, \& D.

Monsalve, Derecho y lógicas de la justicia.

Un análisis socio-jurídico desde la academia, 4-68. Ciudad de México: Anaya Ed. 